\title{
El Romancero en la Edad Media: discurso tradicional y literatura culta
}

\section{The Romancero in the Middle Ages: Traditional Discourse and Cultured Literature}

\author{
Gloria Chicote \\ Conicet-Universidad Nacional de La Plata \\ gchicote@yahoo.com
}

El género romancero tiene un comportamiento propio que no permite encasillamientos fijos. Ha llegado hasta la actualidad diversificado a través de las tradiciones oral y escrita, y dentro de la escrita, particularmente la impresa; mas, estas tradiciones han estado relacionadas entre sí desde el nacimiento del fenómeno, han navegado juntas en el fluir de la tradicionalidad, y podemos decir que resulta prácticamente imposible considerarlas individualmente.

El presente artículo propone un recorrido a través de las primeras fijaciones escritas del género en cancioneros y pliegos sueltos para tratar de desentrañar los nexos entre discurso tradicional y prácticas escriturales.

Asimismo se interroga si el corpus cerrado y extremadamente selecto documentado en los siglos XV y XVI refleja el desarrollo integral del género, o simplemente testimonia los gustos de una élite culta y poderosa.

Palabras Clave: romancero, siglos XV y XVI, cancioneros, pliegos sueltos

The Romance genre has its own behavior that does not allow fixed typecasting. It has reached the present context diversified through oral and written traditions, and within the written, particularly the printed. However, these traditions have been related to each other since the birth of the phenomenon, they have navigated together in the flow of traditional culture, and we can say that it is practically impossible to consider them individually.

This article proposes an approximation through the first written fixations of the genre in songbooks and loose sheets to try to unravel the links between traditional discourse and scriptural practices.

It also questions whether the closed and extremely select corpus documented in the 15 th and 16th centuries reflects the integral development of the genre, or simply testifies to the tastes of a cultured and powerful elite.

KEYWORDS: romancero, $15^{\text {th }}$ and $16^{\text {th }}$ centuries, songbooks, loose sheets 
1 - Cuando abordamos un objeto de estudio que integra el conjunto de manifestaciones culturales se hace indispensable, como recurso metodológico, efectuar un recorte de los aspectos a tratar en un esfuerzo por delimitarlo y extraerlo del todo al que pertenece. Pero también es evidente que ese contexto móvil, fijado únicamente por los intereses del investigador e inexistente en la realidad, siempre está presente en el análisis, aunque se focalice desde distintos ángulos que privilegien una u otra visión.

Tal es el caso del Romancero español. En tanto producto cultural que no ha cerrado su ciclo de vigencia, el romance tiene un comportamiento propio que no permite encasillamientos fijos. Ha llegado hasta la actualidad diversificado a través de las tradiciones oral y escrita, y dentro de la escrita, particularmente la impresa; mas, estas tradiciones han estado relacionadas 14 entre sí desde el nacimiento del fenómeno, han navegado juntas en el fluir de la tradicionalidad, y podemos decir que resulta prácticamente imposible considerarlas individualmente.

2. Si bien el estudio del romancero oral contemporáneo se torna muy complejo debido a la cantidad de versiones constantemente renovadas que se esparcen en las distintas regiones del mundo de habla hispana, no resulta más sencillo el abordaje de los textos romancísticos medievales. Frente al corpus procedente de cancioneros, pliegos sueltos o copias manuscritas, documentados a lo largo de los siglos XV y XVI, el investigador se hace una serie de preguntas:

* ¿En qué medida estos poemas poseen las características del discurso tradicional, su apertura y dinamismo ${ }^{1}$

* ¿Cuánto han perdido o modificado los romances en su fijación escrita, que es, por otra parte, el único testimonio que nos queda de su existencia?

* ¿Hasta qué punto un corpus cerrado y extremadamente selecto, como es el que nos llega de los siglos XV y XVI, refleja el desarrollo integral del género, o simplemente testimonia los gustos de una élite culta y poderosa?

Cabe señalar que estas dudas no son exclusivas del romancero, sino que pueden hacerse extensivas a todas las manifestaciones literarias medievales de génesis y difusión oral, como la lírica tradicional, los cantares de gesta, o algunas

${ }^{1}$ El desarrollo más exhaustivo sobre las características del romancero tradicional puede consultarse en Catalán, Catálogo, t.1A. 
especies de la narrativa breve, que accedieron al ámbito de la escritura de la mano de intereses culturales específicos de cada periodo, y en las cuales se ha operado una traducción de códigos que dificulta su análisis.

En relación con la impronta oral del género, se halla la ausencia de apreciaciones sistemáticas referidas al fenómeno que nos ocupa en la literatura "culta" de la época. Para hallar respuestas certeras proponemos orientar la búsqueda al análisis de los textos en su conjunto, sus relaciones contextuales e intertextuales y las marcas de su recepción, como elementos que contribuyen a establecer las claves de su naturaleza. Con este propósito nos referiremos al fenómeno romancero desde sus orígenes hasta 1550, periodo que caracterizamos como la primera etapa de manifestación del romance en el mundo literario, a través de su fijación escrita, cuyo cierre lo marca la aparición del Cancionero de romances, Amberes sin año y $1550 .^{2}$

3. Aunque podemos suponer que los primeros romances fueron compuestos en el siglo XIII (Menéndez Pidal, Romancero, t.1, cap. V), las documentaciones datan de la primera mitad del siglo Xv. Curiosamente, una especie que reconocemos como de honda raigambre castellana no se manifiesta en esta primera etapa en su tierra de origen, Castilla, sino en zonas periféricas. Los primeros romances transcritos provienen de colectores extranjeros: en 1421, el mallorquín Jaume de Olesa copia en un códice florentino el romance de "La dama y el pastor" (Levi, "Romance florentino"), y alrededor de 1450, un gallego, Juan Rodríguez del Padrón, transcribe, tres romances, "Rosaflorida”, "Infante Arnaldos" y "La hija del rey de Francia", junto con otras obras de su propia invención conservadas en el Cancionero de Londres.

Contemporáneamente a estas documentaciones, la referencia al romancero aparece acallada en Castilla, si no es por los comentarios adversos que recibe desde la preceptiva literaria y la poesía cortesana: la conocida Carta del Marqués de Santillana, ${ }^{3}$ y los versos del Laberinto de fortuna de Juan de Mena, ${ }^{4}$ dan prueba de ello.

En dicho periodo el romance parece excluido de la poesía cortesana, los hombres de letras no los reconocen dentro de sus intereses estéticos, aunque

\footnotetext{
2 Para una referencia completa al estado actual de los estudios sobre este periodo, remitimos a Piñero et al. (eds.), El Romancero.

3 “[... ] ínfimos son aquellos que sin ningún orden, regla nin cuento facen estos romances o cantares de que las gentes de baja e servil condición se alegran $[\ldots]$ ” (p. 7).

4 “[... del que se dice morir emplazado / de los que de martos ovo despeñado / segund dizen los rústicos d'esto cantando” (p. 182).
} 
testimonian, a través de comentarios adversos, el proceso de transmisión oral que se está operando en el contexto sociocultural. Son mencionados como poemas cantados por "rústicos" y "gente de baja y servil condición”, pero, confrontando estas afirmaciones con los elaborados textos que se fijarán en los años siguientes, es pertinente adherirlos a la tesis de Ramón Menéndez Pidal, que considera los primeros romances como representantes de un ambiente caballeresco, culto, aunque no cortesano, destinados a la recreación en una etapa oral-musical.

4. Una vida intensa, aunque oculta, del romance se pone de manifiesto en el cambio del gusto literario que se opera a partir de 1450: el romance tradicional y las imitaciones realizadas por poetas cultos aparecen cada vez con más frecuencia en los cancioneros palaciegos (Cancionero de Londres, Cancionero 16 musical) y en los cancioneros particulares (Cancionero de Juan del Encina, Cancionero de Fray Ambrosio Montesino).

En la segunda mitad del siglo xv altos personajes de la corte comienzan a encargar a hombres de letras la composición de romances artificiosos que retoman las funciones primigenias del poema tradicional: informar y recrear. Recuperando la esencia de los romances noticieros, Enrique IV hizo escribir un romance para la conmemoración de una victoria en Granada, y la muerte del príncipe Alfonso de Portugal fue inmediatamente cantada en versos de romance por Fray Ambrosio Montesino (Menéndez Pidal, Romancero, II, 19). En la misma época, el "Juego de Naipes" de Pinar nos pone en conocimiento de los romances que se cantaban habitualmente en la corte de los Reyes Católicos.

Ha comenzado la etapa en que el romance se precipita a la tradición escrita, en la cual marcaremos tres hitos representativos que evidencian distintos pasos en la documentación: el Cancionero General de Hernando del Castillo de 1511, el conjunto de pliegos sueltos aparecidos con posterioridad a esta fecha y a lo largo del siglo XVI, y el Cancionero de romances de Amberes s.a. editado por Martín Nucio.

5. El Cancionero General es el primero que incluye una sección especial de romances; en este sentido, ofrece la novedad de un intento de publicación sistemática del género (Orduna, "Sección de romances"). En oposición a las documentaciones anteriores que habían sido apariciones esporádicas, y lentamente se habían ganado el reconocimiento de los hombres cultos, Hernando del Castillo inicia un proceso de fijación textual con caracteres específicos. Aparecen en su Cancionero textos de diversa procedencia reunidos durante veinte años de compilación (Dutton, "Desarrollo"). En este contexto, la sección de romances del Cancionero General evidencia la determinación de editar 
un conjunto de poemas, imitadores de los romances tradicionales, pero compuestos especialmente para un público cortesano. Los textos conforman una unidad poética artificiosa, que no se ha desgajado de la tradición oral, sino que surge de la adecuación del metro romancístico al ámbito lírico propio de la poesía de cancioneros. La forma original del romance oral es "adornada" por los poetas cultos de fines del siglo XV y comienzos del XVI, con las "galas" de la poesía cortesana: la rima se torna consonante, la serie octosilábica se acompaña con artificios, como villancicos, glosas o deshechas, y la temática se reduce a desarrollos novelescos o amorosos, que los tornan reducibles a los cánones del amor cortés. Se eligen del mundo oral los romances tradicionales que se adaptan a esta concepción literaria, y luego se los reescribe en imitaciones constantes. Entre los romances documentados hasta el Cancionero General podemos destacar ciertos tipos que recurren, como "Fontefrida", "El prisionero", "El conde Claros" "que han sido objeto de reelaboraciones en diferentes cancioneros.

En esta temprana etapa documentamos 143 romances dispersos en textos de diversa procedencia, tales como cancioneros, crónicas, la Gramática de Nebrija, o copias manuscritas; 74 son composiciones de los poetas cortesanos, y 69 tradicionales, de los cuales únicamente 24 aparecen transcritos en su forma original, mientras que el resto son menciones que se hacen a pocos versos o sirven de base para desarrollos artificiosos. ${ }^{6} \mathrm{Si}$ intentamos una conclusión con cifras estimativas, diremos que un $17 \%$ de los poemas estudiados son romances viejos, de tradición oral, y un $83 \%$ son proyecciones cultas, ya sean formas trovadorescas, glosas, contrahechuras o continuaciones de formas originariamente orales.

Los grandes temas de la épica castellana, el ciclo del Cid, los Infantes de Lara, los romances carolingios protagonizados por los héroes épicos franceses, Roldán, Doña Alda, el rey Marsín, entre otros, no tienen lugar en esta primera etapa de recolección escrita, pero continúan su camino de oralidad para aparecer más tarde en una profusión de pliegos sueltos.

6. El Cancionero General edita un grupo selecto de romances artificiosos; esta sección se hace eco de un movimiento de difusión romancística que desde la

${ }^{5}$ Judith Seeger ("Conde Claros") señala marcas de tres tradiciones diferentes: la juglaresca, la tradicional-oral y la escrita, en el romance de "Don Claros de Montalbán".

${ }^{6}$ Los romances aparecen continuados, contrahechos, acompañados por glosas, estribillos, villancicos y deshechas. La versificación de los poemas también adquiere características específicas: uso de rima consonante, predominio de formas breves en los romances viejos y regularización métrica de los versos. 
oralidad impregna la escritura (García de Enterría, "Romancero"). A partir de entonces se desencadena una ola de publicaciones que siguen sendas opuestas. Por una parte, continúa apareciendo después de 1511 una serie de cancioneros y cancionerillos que transcriben o imitan los poemas reunidos por Hernando del Castillo; entre ellos se destaca el "Libro en el cual se contienen cincuenta romances" c. 1525, publicado en Barcelona por Caries Amorós (Rodríguez Moñino, Diccionario, No. 936). Por otra parte, la tradición oral que había inspirado a los poetas cultos, muestra sus frutos originales en una nueva modalidad editorial, los pliegos sueltos (Rodríguez Moñino, Diccionario) que inundan el mercado desde comienzos del siglo XVI.

Estos folletos baratos, que se venden en las ferias urbanas y son adquiridos por un público variado, desde caballeros, damas de la burguesía, criados deseosos de conocer la moda, hasta bibliófilos como Fernando Colón, configuran, como se sabe, un tipo de literatura denominada "de cordel" que participa de las características de lo que más tarde se manifestará como un elemento constitutivo de la cultura de masas: productos lanzados en gran escala, dirigidos a un público amplio y heterogéneo (Eco, Apocalípticos).

En los pliegos sueltos afloran los textos que desde el anonimato oral habían determinado la aparición de los romances artificiosos. Los grandes temas del romancero derivados de la épica y la baladística europea serán fijados en esta temprana etapa de la imprenta. Tradición oral y escrita se interrelacionan formando un único ciclo de conexiones. Los poemas orales son inspiradores de una tradición escrita de romances artificiosos que aparecen en los cancioneros cortesanos, en los que se hacen presentes, aún en sus disfraces y modificaciones. Los textos procedentes de la cultura oral se vuelcan en los pliegos sueltos donde la tradición escrita amplía los límites temáticos y estilísticos propuestos por los cancioneros y debe acudir nuevamente al mundo oral en búsqueda de productos que alimenten el nuevo gusto de un público cada vez más diverso. Sin duda, en el siglo xvi con la difusión de la imprenta, se afianza el camino de "literaturidad" que llega hasta nosotros, aunque esa ruta nunca deja de ser transitada por formas orales. ${ }^{7}$

7. Dicho movimiento de mostración y ocultación caracteriza la documentación del romancero medieval hasta mediados del siglo XvI, fecha en que la

\footnotetext{
${ }^{7}$ Los nexos entre oralidad y escritura que señalamos en el mundo medieval se continúan en toda la literatura del Siglo de Oro. La caracterización de las relaciones entre letra y voz en los siglos XVI y XVII ha sido tratada exhaustivamente por Margit Frenk en diversos trabajos ("Lectores", "Ver, oír", "La ortografía”, etc).
} 
aparición del Cancionero de romances de Amberes s.a., marca un cambio de rumbo en la historia del romancero escrito, que consideraremos como tercer momento y último hito de nuestro análisis.

¿Qué función cumple el Cancionero de romances en este enfrentamiento y juego implícito de retroalimentaciones entre oralidad y escritura? Martín Nucio concibe su Cancionero como una obra de divulgación. A diferencia del Cancionero General, que había sido compuesto para la corte, su obra está dirigida a un sector más amplio de la población, a un espectro social heterogéneo que va desde la nobleza culta hasta la burguesía incipiente; está destinado al público lector en general, y su propósito, de alguna manera universal, de llegar a modalidades y gustos diferentes, se evidencia en la composición del libro.

El Cancionero de romances capta la totalidad del proceso que acabamos de describir. Reúne los poemas que provienen de la tradición oral (a través de recitaciones proporcionadas por informantes, e indirectamente, copiando versiones manuscritas o transcribiendo pliegos sueltos), con los que derivan de la tradición escrita recientemente difundida (cancioneros, cancionerillos y algunos pliegos sueltos). Sin embargo, una nueva orientación se perfila en esta obra: la tradición oral impone su forma predominante de octosílabos asonantados, completa todo su panorama temático y se libera de los artificios impuestos por la poesía cortesana.

Martín Nucio se presenta como el primer colector moderno del romancero. Es muy significativa la introducción al cancionero, en la que muestra a los lectores cuál fue su actitud ante los poemas reunidos, en cuanto a la determinación de su procedencia y su afán clasificatorio:

El impresor:

He querido tomar el trabajo de juntar en este cancionero todos los romances que han venido a mi noticia; pareciéndome que cualquiera persona para su recreación y pasatiempo holgaría de lo tener, porque la diversidad de historias que hay en él dichas en metro y con mucha brevedad será a todos agradable. Puede ser que falten aquí algunos (aunque no muchos) de los romances viejos los cuales yo no puse o porque no han venido a mi noticia o porque no los hallé tan cumplidos y perfectos y no niego que en los que aquí van impresos habrá alguna falta pero esta se debe imputar a los ejemplares de adonde los saqué que estaban muy corruptos y a la flaqueza de la memoria de algunos que me los dictaron que no se podían acordar de ellos perfectamente. Yo hice toda diligencia porque hubiese las menos faltas que fuese posible y no me ha sido poco trabajo juntarlos y enmendar y añadir algunos que estaban imperfectos. También quise que tuviesen alguna orden y puse primero los que hablan de 
las cosas de Francia y de los doce pares después los que cuentan historias castellanas y después los de Troya y últimamente los que tratan cosas de amores pero esto no se pudo hacer tanto a punto (por ser la primera vez) que al fin no quedase alguna mezcla de unos con otros. Querría que todos se contentasen y llevasen en cuenta mi buena voluntad y diligencia. El que así no lo hiciere haya paciencia y perdóneme que yo no pude más.

Vale.

El Cancionero de Amberes representa la conclusión de una etapa que se venía gestando en los años anteriores: la definitiva aceptación del género romancístico entre los hombres de letras de la corte castellana, hecho que determina una nueva senda en la historia de la fijación de romances. Le su-

20 cederán el Cancionero de romances de 1550, la Silva de Zaragoza, y la serie de "Romanceros viejos" publicados hasta 1589 , en que empiezan a aparecer las "Flores" de romances nuevos, con textos surgidos de la pluma de los grandes escritores del Siglo de Oro. Será el momento de gran divulgación del romancero y tendrá también características propias que requieren un nuevo análisis que considere, por ejemplo, la irrupción masiva de formas y motivos romancísticos en el teatro, la tradicionalización de textos de origen literario (proceso de signo contrario al que acabamos de describir), y la relación del romance con la narrativa en prosa.

Los romances documentados en los siglos XV y XVI se convirtieron en poesía escrita a partir de una traducción de códigos. Fueron despojados de sus marcas de oralidad, de la apertura que propiciaba su vida en variantes, para acceder a los cancioneros palaciegos y fijarse en los cánones de una poesía artificiosa. Más tarde, los pliegos sueltos que testimonian la difusión de la especie entre capas más amplias de la sociedad, transcriben textos cada vez más próximos a su entorno oral; no se reniega de la génesis de estos poemas, sino que de algún modo les son devueltos sus rasgos primitivos. Cerrando este movimiento, el Cancionero de romances de Amberes s.a. documenta romances que evidencian su ascendencia oral, presenta un panorama amplio del fenómeno que ya está preparado para su irrupción masiva en la literatura del Siglo de Oro.

\section{BIBLIOGRAFÍA}

Cancionero General, recopilado por Hernando del Castillo (Valencia, 1511), reproducido en facsímil con intr. bibl. índice y apéndices de Antonio Rodríguez Moñino, Madrid: 1958. 
Cancionero de Londres, ed. de H. Rennert, Roman Forschungen, X, 1899, 1-176.

Cancionero musical español de los siglos XV y XVI, transcrito y comentado por Francisco Asenjo Barbieri, Buenos Aires: 1945.

Cancionero de romances, editado por Martín Nucio (Amberes). Edición facsímil e introd. de Ramón Menéndez Pidal, Madrid: CSIC, 1945.

Catalán, Diego, et al., Catálogo general de Romancero panhispánico, Madrid: Gredos, Seminario Menéndez Pidal, 1982-1984.

DutTon, Brian, “El desarrollo del Cancionero General de 1511”, ed. de Enrique Rodíguez Cepeda, Actas del Congreso Romancero-Cancionero, UCLA (1984), Madrid: Porrúa Turanzas, 1990, 81-96.

ECo, Umberto, Apocalípticos e integrados ante la cultura de masas, Barcelona: Lumen, 1968.

EnCina, JuAn Del, Cancionero [1496], Madrid: Real Academia Española, 1928.

Frenk, Margit, "Lectores y oidores. La difusión oral de la literatura en el Siglo de Oro", Actas del VII Congreso de la Asociación Internacional de Hispanistas, Roma: Bulzoni, 1982, I, 101-123.

Frenk, MARgit, “Ver, oír, leer...”, en Lia Shwartz Lerner e Isaías Lerner (eds.), Homenaje a Ana María Barrenechea, Madrid: Castalia, 1984, 235-240.

Frenk, Margit, "La ortografía elocuente (Testimonios de lectura oral en el Siglo de Oro)", Actas del VIII Congreso de la Asociación Internacional de Hispanistas, Madrid: 1986, 549-556.

Frenk, MARGit, "La poesía oralizada y sus mil variantes”, Anuario de Letras, XXIX, 1991, 133-144.

García de Enterria, María Cruz, “Romancero: ¿cantado, recitado, leído?”, Edad de Oro, VII, 1988, 89-104.

LEVI, EzIo, “El romance florentino de Jaume de Olesa”, Revista de Filología Española, 1927, 134-160.

López de Mendoza, Íñıgo, (Marqués de Santillana), Obras, ed. de Amador de Los Ríos, Madrid: 1852.

Mena, Juan de, Laberinto de fortuna, ed. de J. C. Cummins, Madrid: 1979.

Menéndez Pidal, Ramón, Romancero Hispánico, 2 vols., Madrid: Espasa Calpe, 1953.

Montesino, Ambrosio, Cancionero, Biblioteca de Autores Españoles, t. XXXV, Madrid: 1855, 401-466.

Orduna, Germán, "La sección de romances en el Cancionero General (Valencia, 1511): recepción cortesana del romancero tradicional”, Literary Studies in Memory of Keith Whinnom, Liverpool: Liverpool University Press, 1989, 113-122.

Piñero, Pedro et al. (eds.), El Romancero. Tradición y pervivencia a fines del siglo $x x$. Actas del IV Coloquio Internacional del Romancero, Sección II: El Romancero en los siglos xv y xvi, Cádiz: Fundación Machado, 1989. 
Rodríguez Moñino, Antonio, Diccionario bibliográfico de pliegos sueltos poéticos (siglo XVI), Madrid: Castalia, 1970.

Seeger, Judith, “El ‘Conde Claros de Montalbán’ en el siglo xvi. Evidencia de la vitalidad de tres tradiciones: la juglaresca, la tradicional y la escrita”, en Pedro Piñero et al. (eds.), El Romancero. Tradición y pervivencia a fines del siglo xx, Cádiz: Fundación Machado, 1989, 237-242. 